\title{
Promoter hypermethylation of cysteine dioxygenase type 1 in patients with non-small cell lung cancer
}

\author{
WEI YIN ${ }^{1}$, XIANG WANG ${ }^{1}$, YUNPING LI $^{2}$, BIN WANG $^{1}$, MINGZHE SONG ${ }^{1}$, \\ ALICIA HULBERT $^{3}$, CHEN CHEN $^{1}$ and FENGLEI YU ${ }^{1}$ \\ Departments of ${ }^{1}$ Thoracic Surgery and ${ }^{2}$ Ophthalmology, The Second Xiangya Hospital of \\ Central South University, Changsha, Hunan 410011, P.R. China; ${ }^{3}$ Department of Surgery, \\ University of Illinois at Chicago School of Medicine, Chicago, IL 60607, USA
}

Received May 30, 2019; Accepted February 28, 2020

DOI: $10.3892 / \mathrm{ol} .2020 .11592$

\begin{abstract}
In the present study, promoter hypermethylation of cysteine dioxygenase type 1 (CDO1) was evaluated in non-small cell lung cancer (NSCLC) tissues to assess the value of CDO1 as a novel biomarker to improve the diagnosis of NSCLC. Tumor tissue samples and corresponding normal lung tissue samples from 42 patients with NSCLC were obtained at the Department of Thoracic Surgery, The Second Xiangya Hospital (Changsha, China). Conventional methylation-specific PCR (cMSP) and methylation-on-beads followed by quantitative methylation-specific PCR (MOB-qMSP) were used to analyze the tumor and normal lung tissue samples. Using these two methods, promoter DNA hypermethylation of the CDO1 gene was detected in 59.4 and $71.0 \%$ of tumor tissues of patients with NSCLC and in 9.4 and $0 \%$ of normal lung tissue, respectively. Compared with the rate of methylation in the well-differentiated NSCLC tissues (15.4 and 55.6\%, respectively), the rate of CDO1 gene promoter methylation was higher in the poorly differentiated tissues (89.5 and 92.3\%, respectively). Overall, it was demonstrated that the MOB-qMSP method had a higher positive detection rate for CDO1 hypermethylation compared with the cMSP method. In conclusion, CDO1 gene promoter hypermethylation was more frequently observed in NSCLC tissues compared with in normal lung tissues, and a high methylation frequency of the CDO1 gene in biopsy specimens of NSCLC was associated with the degree of differentiation.
\end{abstract}

\section{Introduction}

According to global cancer incidence and mortality statistics in 2012, lung cancer has remained the most common

Correspondence to: Professor Fenglei Yu, Department of Thoracic Surgery, The Second Xiangya Hospital of Central South University, 134 Renmin Middle Road, Changsha, Hunan 410011, P.R. China E-mail: yufenglei@csu.edu.cn

Key words: cysteine dioxygenase type 1, non-small cell lung cancer, methylation, methylation-specific PCR, diagnosis malignant tumor type worldwide and has accounted for the highest number of cancer-associated mortalities (1). In 2015, $>4$ million new cases of cancer and $\sim 3$ million cancer-associated mortalities occurred in China, including $\sim 733,000$ new lung cancer cases and 610,000 lung cancer-associated deaths (2). The average 5-year survival rate for all cases of lung cancer combined is just $16.8 \%$ (3), while it is $55 \%$ for localized lung cancers, $27 \%$ for regional metastasis and $4 \%$ for distant metastasis (4). However, the majority of patients with lung cancer are diagnosed at an intermediate or late stage and, thus, have missed the best opportunity to be cured (4). Therefore, to improve the overall survival rate of patients with lung cancer, it is important to focus on early diagnosis and treatment of lung cancer.

Recent advancements in the promising field of epigenetics have identified a strong association between cancer and epigenetics. DNA methylation is one of the earliest and most important types of epigenetic modification and has an important role in regulating growth, gene expression and genomic stability (5). In previous years, numerous studies have demonstrated that hypermethylation of $\mathrm{CpG}$ islands is associated with gene silencing and is an important molecular change during the development of cancer $(6,7)$. In the early stages of cancer, even prior to imaging scans, abnormal DNA methylation may be detected. Therefore, analysis of DNA methylation may be a powerful tool for early diagnosis of lung cancer (8).

Herman et al (9) described conventional methylation-specific PCR (cMSP) that is able to rapidly assess the methylation status of the majority of $\mathrm{CpG}$ sites within a $\mathrm{CpG}$ island. This simple and sensitive method is currently the most widely worldwide. However, during cMSP, bisulfite modification-induced DNA damage and degradation can markedly reduce the sensitivity of methylation detection. As technology advances, quantitative PCR (qPCR) may replace conventional $\mathrm{PCR}$ and $\mathrm{qPCR}$ is more sensitive and specific compared with cMSP and has a reduced likelihood for operational contamination (10). Hulbert et al (11) modified the magnetic bead method to extract DNA, reduced the degradation of DNA during the bisulfite process and combined it with qPCR for detection with higher sensitivity and specificity. This process was named methylation-on-beads followed by quantitative methylation-specific PCR (MOB-qMSP). 
Cysteine dioxygenase type 1 (CDO1) is a mammalian non-heme iron enzyme, the major functions of which are regulation of cysteine levels and participation in metabolic pathways of compounds, including pyruvate and taurine (12). $\mathrm{CDO} 1$ is also a tumor suppressor enzyme and previous studies have demonstrated that $\mathrm{CDO} 1$ gene promoter methylation leads to silencing of this gene in the development of various types of cancer, including breast cancer (13), hepatocellular cancer (14), gallbladder cancer (15), colorectal cancer (16), gastric cancer (16), prostate cancer (17) and esophageal squamous cell carcinoma (18). In studies investigating lung cancer, methylation of the $\mathrm{CDO} 1$ promoter has been observed; Feng et al (19) confirmed the association of this with non-small cell lung cancer (NSCLC) and Hulbert et al (11) indicated that methylation of the CDO1 promoter has good sensitivity and specificity for detecting lung cancer. However, the vast majority of research available is based on European or American populations and only few studies have been performed among Asian patients. To the best of our knowledge, the present study was the first to use MOB-qMSP to detect CDO1 methylation in China, providing an important reference for the identification of CDO1 gene methylation in Asian patients with NSCLC.

\section{Materials and methods}

Patients and samples. In the present study, 42 patients diagnosed with NSCLC were included. The cohort included 30 males and 12 females with a mean age of 60 years (range, 33-83 years). All patients were enrolled from the Department of Thoracic Surgery, The Second Xiangya Hospital of Central South University (Changsha, China) between August 2017 and January 2018. Prior to surgery, all patients received assessments including CT scan of the chest, MRI scan of the brain, color Doppler ultrasound of the abdomen and a radionuclide bone scan. Surgical resection and pathological analyses were performed in all patients and staging was performed according to the most recent Tumor-Node-Metastasis (TNM) guidelines (20). Of the 42 tumor tissue samples, 25 were adenocarcinoma and 17 were squamous cell carcinoma. The matched adjacent normal lung tissues were confirmed by pathologists. The present study was approved by The Ethics Committee of the Second Xiangya Hospital (Changsha, China) and written informed consent was provided from the patients. Tumor and normal tissues were collected immediately after excision and stored at $-80^{\circ} \mathrm{C}$.

DNA extraction and methylation analysis. Two methods were used for DNA extraction from tissue and bisulfite conversion (kits were used according to the manufacturer's protocol: i) cMSP including the use of a traditional DNA Purification kit (DP304 TIANamp Genomic DNAkit, Qiagen China Co., Ltd.) and an EZ DNA Methylation kit (D5005 EZ DNA Methylation-Gold kit, Zymo Research Corp.) and ii) MOB-qMSP, including the use of silica super magnetic beads (cat. no. MD1471 MagneSil KF; Paramagnetic Particles; Promega Corporation) in the process of DNA isolation and bisulfite conversion (11). The methylation and unmethylation CDO1 gene primers were designed using Methyl Primer Express 1.0 (Thermo Fisher Scientific, Inc.) and a TaqMan probe and $\beta$-actin primers were used (Table I).
DNA extraction from samples was performed using $30 \mathrm{mg}$ of tissue and $40 \mu \mathrm{l}$ Proteinase K (Qiagen China Co., Ltd.). After digestion and multiple elution, CT Conversion reagent was used for DNA bisulfite conversion to obtain the methylated DNA. cMSP was performed in a 50- $\mu 1$ PCR mixture consisting of 9.25 $\mu 1$ Premix Ex Taq (Takara Bio, Inc.), $1 \mu 1$ forward primer, $1 \mu \mathrm{l}$ reverse primer, $2 \mu \mathrm{l}$ DNA and $36.75 \mu \mathrm{l}$ water. The thermocycling conditions included 35 cycles of $98^{\circ} \mathrm{C}$ for $10 \mathrm{sec}$, $60^{\circ} \mathrm{C}$ for $30 \mathrm{sec}$ and $72^{\circ} \mathrm{C}$ for $60 \mathrm{sec}$. After amplification, each PCR product mixture was separated on a $2 \%$ agarose gel, added nucleic acid gel stain (cat. no. GG1301; 500 $\mu 1$ GenGreen nucleic acid gel stain; Beijing Dingguo Changsheng Biotechnology Co., Ltd.) and visualized under Blue Light Gel Imager (wavelength, $440 \mathrm{~nm}$; cat. no. G500312-0001; Sangon Biotech Co., Ltd.) in room temperature.

Modification technology-based magnetic beads were used for DNA extraction and bisulfite conversion (11). For DNA extraction, $30 \mathrm{mg}$ of tissue was added to $300 \mu \mathrm{l}$ Buffer AL and $40 \mu 1$ Proteinase K (Qiagen China Co., Ltd.), followed by incubation $\left(50^{\circ} \mathrm{C}\right.$, overnight). After DNA bisulfite conversion on magnetic beads, the methylated DNA was obtained. MOB-qMSP was performed in 20- $\mu$ PCR mixture consisting of $10 \mu \mathrm{l}$ Premix Ex Taq, $0.4 \mu \mathrm{l}$ forward primer, $0.4 \mu \mathrm{l}$ reverse primer, $0.8 \mu 1$ probe, $0.4 \mu 1$ ROX Reference Dye, $2 \mu 1$ DNA and $6 \mu 1$ water. An ABI StepOnePlus Real-Time PCR system (Applied Biosystems; Thermo Fisher Scientific, Inc.) was used for the reaction with the following conditions: $95^{\circ} \mathrm{C}$ for $20 \mathrm{sec}, 45 \mathrm{cycles}$ at $95^{\circ} \mathrm{C}$ for $1 \mathrm{sec}$ and $60^{\circ} \mathrm{C}$ for $20 \mathrm{sec}$. After amplification, the results were directly observed on the ABI StepOnePlus Real-Time PCR system.

Statistical analysis. All data were analyzed with SPSS 21.0 statistical software (IBM Corp.). The rate of DNA methylation was assessed using the $\chi^{2}$ or Fisher's exact test. The two detection methods for CDO1 gene methylation were compared using McNemar's test. $\kappa$ statistics were used to evaluate the concordance between the two methods. $\mathrm{P}<0.05$ was considered to indicate statistically significant difference.

\section{Results}

Patient characteristics. The general data and pathological features of the 42 patients are summarized in Table II. Subjects with smoking indexes of $\geq 400$ and $<400$ were equally represented. Among the pathological features, adenocarcinoma accounted for $62 \%$ of cases, while squamous cell carcinoma accounted for $38 \%$ of cases. According to the TNM staging system, 32 cases were in the early stages (I/II) and 10 cases were in the late stages (III/IV). Regarding the degree of tumor differentiation, there were 20 cases of high/moderate differentiation and 22 of poor differentiation.

In the present study, the promoter DNA methylation levels of the CDO1 gene in tissues from 42 patients with NSCLC were compared; in 32 cases, cMSP was used and MOB-qMSP was used in 31 cases. The results obtained with the two methods indicated that $\mathrm{CDO} 1$ methylation was significantly higher in tumor tissues compared with normal tissues. Of the 32 cases assessed using cMSP, CDO1 methylation was detected in 19 tumor tissues and in 3 normal lung tissues. Of the 31 cases assessed using MOB-qMSP, CDO1 methylation 
Table I. PCR primers and TaqMan probes for conventional methylation-specific PCR and methylation-on-beads followed by quantitative methylation-specific PCR.

\begin{tabular}{ll}
\hline Gene & \multicolumn{1}{c}{ Primer sequence $\left(5^{\prime}-3^{\prime}\right)$} \\
\hline $\begin{array}{l}\text { CDO1, methylation } \\
\text { Forward } \\
\text { Reverse }\end{array}$ & TTTTTGGGACGTCGGAGATAAC \\
CDO1, unmethylation & CGAAAAAACCCTACGAACACG \\
Forward & \\
Reverse & GATTTTTGGGATGTTGGAGATAAT \\
CDO1 & AAAACAAAAAAACCCTACAAACACA \\
Forward & \\
Reverse & AGGCGGGGAGATTTTGCG \\
Probe & CCTAAAACGCCGAAAACAACG \\
$\beta$-actin & 6FAM-CGGTTTACGCGTATATTTTCGGTTTT-TAMRA \\
Forward & \\
Reverse & TAGGGAGTATATAGGTTGGGGAAGTT \\
Probe & AACACACAATAACAAACACAAATTCAC \\
\hline
\end{tabular}

CDO1, cysteine dioxygenase type 1 .

Table II. Demographic characteristics of 42 patients with NSCLC.

\begin{tabular}{lc}
\hline Characteristic & $\mathrm{n}(\%)$ \\
\hline Age, years & \\
Mean \pm standard deviation & $60 \pm 9.51$ \\
Range & $33-83$ \\
Sex & \\
Male & $30(71)$ \\
Female & $12(29)$ \\
Smoking index & \\
$\geq 400$ & $21(50)$ \\
$<400$ & $21(50)$ \\
Histology & \\
Adenocarcinoma & $26(62)$ \\
Squamous carcinoma & $16(38)$ \\
TNM stage & \\
I/II & $32(76)$ \\
III/IV & $10(24)$ \\
Differentiation & \\
High/moderate & $20(48)$ \\
Poor & $22(52)$ \\
\hline
\end{tabular}

Smoking index, average root number of smoking per day multiplied smoking years; NSCLC, non-small cell lung cancer; TNM, tumor-node-metastasis.

was detected in 22 tumor tissues and in 0 normal lung tissues (Fig. 1; Table III). Furthermore, 21 pairs of samples were assessed with cMSP and MOB-qMSP and the $\kappa$ statistical result of 0.47 indicated a low concordance between the two methods for assessing promoter DNA methylation. In addition, MOB-qMSP had a higher positive detection rate for CDO1 hypermethylation compared with cMSP (Table IV).

Further analysis revealed that CDO1 gene hypermethylation was significantly different between highly/moderately and poorly differentiated tissues $(\mathrm{P}<0.05)$, with the CDO1 methylation rate being higher in poorly differentiated NSCLC tissue. However, no significant association was observed regarding any of the other characteristics assessed (Table V).

\section{Discussion}

In somatic cells, abnormal hypermethylation of the promoter region may lead to silencing and inactivation of tumor suppressor genes, which is one of the important molecular changes in tumor development. Increased levels of gene promoter methylation may contribute to the initiation and progression of NSCLC, indicating a close association between DNA methylation and NSCLC (7). CDO1 gene hypermethylation has been reported in various types of cancer and numerous studies have assessed CDO1 gene promoter methylation levels in lung cancer (21-23). CDO1 has been confirmed to be valuable for the diagnosis of NSCLC (24). Another study indicated that CDO1 may potentially serve as a molecular biomarker for multiple human cancers (25).

cMSP is one of the most widely used techniques to detect DNA methylation of a locus of interest; it is able to detect the methylation status rapidly and with high sensitivity (26). In the process of DNA methylation, high bisulfite concentrations lead to DNA degradation and inappropriate conversion (27), reducing the sensitivity of methylation detection. In the present study, MOB-qMSP was also used to detect the promoter methylation of the target gene whilst reducing the 
Table III. Promoter hypermethylation detection using cMSP and MOB-qMSP in patients with NSCLC.

\begin{tabular}{lcrr}
\hline Method & Tumor tissues, $\mathrm{n}(\%)$ & Normal tissues, $\mathrm{n}(\%)$ \\
\hline cMSP & & & \\
Methylation & $19(59.4)$ & 3 & $(9.4)$ \\
Unmethylation & $13(40.6)$ & 29 & $(90.6)$ \\
MOB-qMSP & & & \\
Methylation & $22(71.0)$ & 0 & $(0.0)$ \\
Unmethylation & $9(29.0)$ & $31(100.0)$ \\
\hline
\end{tabular}

NSCLC, non-small cell lung cancer; cMSP, conventional methylation-specific PCR; MOB-qMSP, methylation-on-beads followed by quantitative methylation-specific PCR.

Table IV. Comparison of two methods to detect CDO1 gene hypermethylation.

\begin{tabular}{lccc}
\hline & \multicolumn{3}{c}{ MOB-qPCR } \\
\cline { 2 - 4 } cMSP & Methylation & Unmethylation & P-value \\
\hline Methylation & 8 & 0 & 0.041 \\
Unmethylation & 6 & 7 & 0.471
\end{tabular}

CDO1, cysteine dioxygenase type 1; cMSP, conventional methylation-specific PCR; MOB-qMSP, methylation-on-beads followed by quantitative methylation-specific PCR.
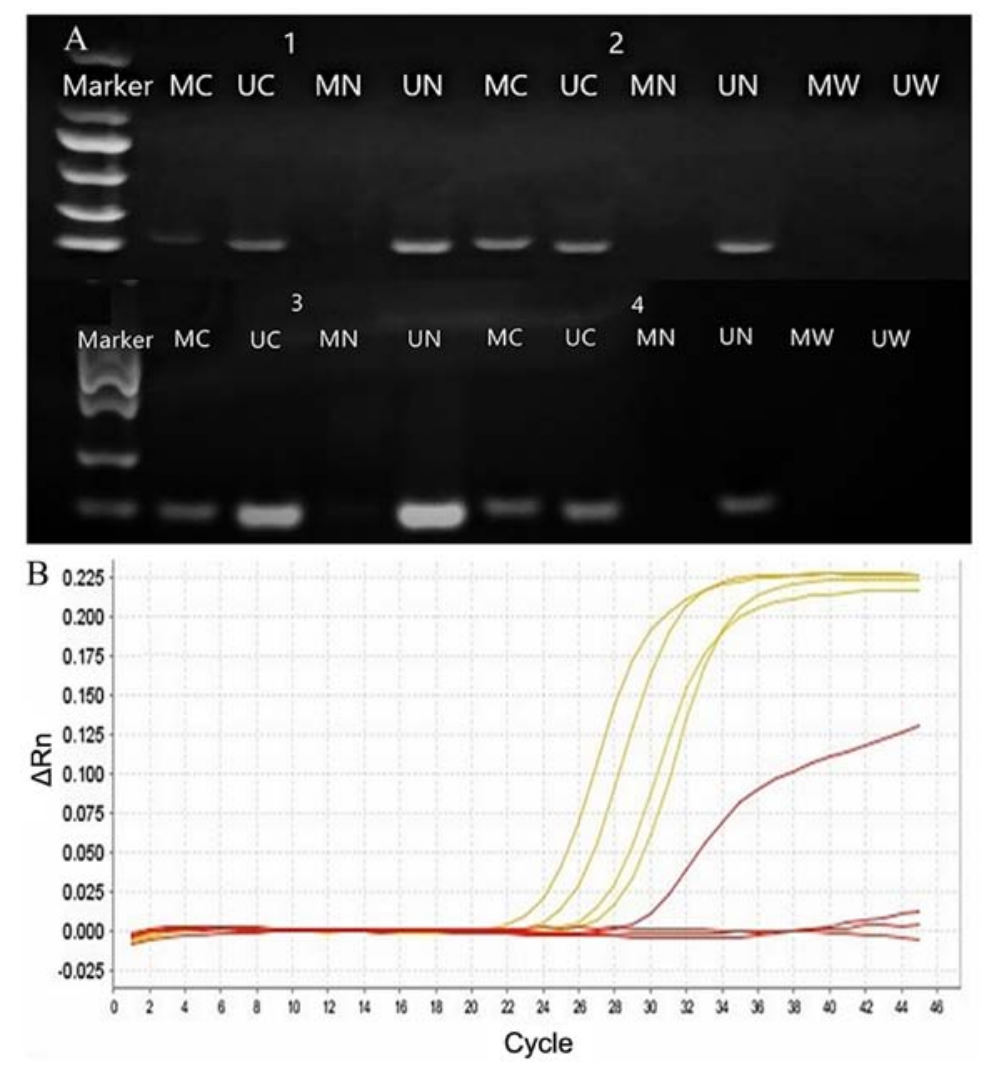

Figure 1. CDO1 gene promoter methylation in NSCLC was detected using gel electrophoresis and quantitative PCR. Numbers 1-4 represent four groups of corresponding tissue samples (tumor vs. normal lung tissue). The DL2000 DNA Marker contains six discrete DNA fragments ranging in size from $100 \mathrm{bp}$ to $2 \mathrm{~kb}$ (100, $250,500,750,1,000$ and 2,000 bp). (A) Amplification of bisulfite-treated CDO1 from cancer and normal tissues. (B) $\beta$-actin, yellow curve; CDO1 gene methylation in tumor tissue, red curve above; CDO1 gene methylation in normal lung tissue, red curve at the bottom. NSCLC, non-small cell lung cancer; CDO1, cysteine dioxygenase type 1; $\mathrm{MC}$ or UC, methylation or unmethylation in tumor tissue; $\mathrm{MN}$ or $\mathrm{UN}$, methylation or unmethylation in normal lung tissue; $\mathrm{MW}$, methylation in water; $\mathrm{UW}$, unmethylation in water. $\Delta \mathrm{Rn}$, normalized reporter value, fluorescence emission of the product at each time point-fluorescence emission of the baseline. 
Table V. Association between promoter hypermethylation of cysteine dioxygenase type 1 and clinical characteristics.

\begin{tabular}{|c|c|c|c|c|c|c|c|c|}
\hline \multirow[b]{2}{*}{ Characteristic } & \multicolumn{4}{|c|}{ cMSP } & \multicolumn{4}{|c|}{ MOB-qMSP } \\
\hline & M & $\mathrm{U}$ & M\% & P-value & M & $\mathrm{U}$ & $\mathrm{M} \%$ & P-value \\
\hline Age, years & & & & 0.149 & & & & 0.054 \\
\hline$\geq 60$ & 13 & 5 & 72.2 & & 14 & 2 & 87.5 & \\
\hline$<60$ & 6 & 8 & 42.9 & & 8 & 7 & 53.3 & \\
\hline Sex & & & & 0.684 & & & & $>0.999$ \\
\hline Male & 15 & 9 & 62.5 & & 16 & 6 & 72.7 & \\
\hline Female & 4 & 4 & 50.0 & & 6 & 3 & 66.7 & \\
\hline Smoking index & & & & 0.149 & & & & 0.113 \\
\hline$\geq 400$ & 12 & 4 & 75.0 & & 13 & 2 & 86.7 & \\
\hline$<400$ & 7 & 9 & 43.8 & & 9 & 7 & 56.3 & \\
\hline Histology & & & & 0.713 & & & & $>0.999$ \\
\hline LUAD & 11 & 9 & 55.0 & & 14 & 6 & 70.0 & \\
\hline LUSC & 8 & 4 & 66.7 & & 8 & 3 & 72.7 & \\
\hline TNM stage & & & & 0.703 & & & & $>0.999$ \\
\hline $\mathrm{I} / \mathrm{II}$ & 13 & 10 & 56.5 & & 17 & 7 & 70.8 & \\
\hline III/IV & 6 & 3 & 66.7 & & 5 & 2 & 71.4 & \\
\hline Differentiation & & & & $<0.001$ & & & & 0.045 \\
\hline High/moderate & 2 & 11 & 15.4 & & 10 & 8 & 55.6 & \\
\hline Poor & 17 & 2 & 89.5 & & 12 & 1 & 92.3 & \\
\hline
\end{tabular}

Smoking index, average root number of smoking per day multiplied smoking years; LUAD, lung adenocarcinoma; LUSC, lung squamous cell carcinoma; cMSP, conventional methylation-specific PCR; MOB-qMSP, methylation-on-beads followed by quantitative methylation-specific PCR; M, methylated; U, unmethylated; TNM, tumor-node-metastasis.

degradation of DNA during the bisulfite conversion process. This method has higher sensitivity and specificity compared with cMSP (11). In the present study, the results obtained with the two methods were consistent, as both methods demonstrated that the methylation rates of CDO1 in tumor tissues from patients with NSCLC were significantly higher compared with those in normal lung tissues $(\mathrm{P}<0.05)$. In addition, the two methods were applied to assess 21 samples in parallel and the results showed that MOB-qMSP had a higher positive detection rate compared with MSP (71.0 vs. 59.4\%). This may be due to the method of combining DNA with magnetic beads prior to bisulfite conversion, which markedly reduces the degradation of DNA and increases the sensitivity of detection (11).

Lung cancer is an age-associated disease (28-30) and alterations in DNA methylation may be due to the harmful effects exerted by tobacco smoking (31). Levine et al (32) indicated that the association between DNA methylation and lung cancer is stronger among older patients and those who are current smokers. Breitling et al (33) suggested that DNA methylation serves a role in a variety of smoking-associated outcomes. Although no statistically significant differences were observed in the present study regarding the association between age or smoking on CD01 methylation levels, there still may be an association between these factors. The lack of significance in the present study may be due to the study limitations, such as a small sample size. High-quality studies with a rational design, including large-scale controlled trials, are required in the future.

In addition, in the present study, no significant difference in CDO1 gene methylation was identified between adenocarcinoma and squamous cell carcinoma, or between the early and advanced stage, which was consistent with the results of Ooki et al (23). However, it is noteworthy that there were statistically significant differences in CDO1 gene methylation between lung cancer tissues with high/moderate and poor differentiation. This suggested that methylation of the CDO1 gene may be an adjuvant marker for evaluating the degree of malignancy of NSCLC; however, further analysis is required to validate these results. For example, it would be valuable to further verify the correlation between CDO1 hypermethylation and NSCLC using in vitro experiments.

In the present study, $\mathrm{CDO} 1$ gene promoter methylation was more frequently observed in lung tumor tissues compared with normal lung tissues and this high methylation frequency of the CDO1 gene was associated with the degree of differentiation of NSCLC. As the degree of differentiation may be linked to the degree of malignancy, CDO1 promoter hypomethylation may have value in evaluating the prognosis of patients with NSCLC. However, further high-quality studies including a larger sample size and regular follow-ups are required to confirm these results.

In conclusion, the present study indicated that CDO1 promoter methylation has a role in NSCLC in the Chinese 
population and that methylation levels are associated with the degree of differentiation of NSCLC. MOB-qMSP has higher sensitivity and specificity compared with cMSP and is more accurate method as it reduces DNA degradation. If confirmed in further studies, detection of CDO1 gene promoter methylation may be used as an adjunct to NSCLC diagnosis, as well as identification of pathological differentiation and guidance for the prognosis of patients with NSCLC.

\section{Acknowledgements}

Not applicable.

\section{Funding}

This work was supported by Hunan Provincial Natural Science Foundation of China (grant no. 2017JJ2364).

\section{Availability of data and materials}

All data generated or analyzed during this study are included in this published article.

\section{Authors' contributions}

CC and FY designed the study concept. WY, XW and MS collected the data of patients. WY, YL, CC and BW analyzed the data. WY drafted the manuscript. $\mathrm{CC}$ and $\mathrm{AH}$ provided technical and material support. AH also participated in the acquisition of data. $\mathrm{CC}, \mathrm{FY}$ and $\mathrm{AH}$ reviewed or revised of manuscript. All authors read and approved the final manuscript.

\section{Ethics approval and consent to participate}

The present study was approved by The Ethics Committee of The Second Xiangya Hospital (Changsha, China; approval no. 2014S006), and written informed consent was provided by all patients.

\section{Patient consent for publication}

Not applicable.

\section{Competing interests}

The authors declare that they have no competing interests.

\section{References}

1. Ferlay J, Soerjomataram I, Dikshit R, Eser S, Mathers C, Rebelo M, Parkin DM, Forman D and Bray F: Cancer incidence and mortality worldwide: Sources, methods and major patterns in GLOBOCAN 2012. Int J Cancer 136: E359-E386, 2015.

2. Chen W, Zheng R, Baade PD, Zhang S, Zeng H, Bray F, Jemal A, Yu XQ and He J: Cancer statistics in China, 2015. CA Cancer J Clin 66: 115-132, 2016.

3. Wender R, Fontham ET, Barrera E Jr, Colditz GA, Church TR, Ettinger DS, Etzioni R, Flowers CR, Gazelle GS, Kelsey DK, et al: American Cancer Society lung cancer screening guidelines. CA Cancer J Clin 63: 107-117, 2013.

4. Miller KD, Siegel RL, Lin CC, Mariotto AB, Kramer JL, Rowland $\mathrm{JH}$, Stein KD, Alteri R and Jemal A: Cancer treatment and survivorship statistics, 2016. CA Cancer J Clin 66: 271-289, 2016.
5. Sharma S, Kelly TK and Jones PA: Epigenetics in cancer. Carcinogenesis 31: 27-36, 2010.

6. Sandoval J,Peiró-Chova L, Pallardó FV and García-Giménez JL: Epigenetic biomarkers in laboratory diagnostics: Emerging approaches and opportunities. Expert Rev Mol Diagn 13: 457-471, 2013.

7. Kim Y and Kim D-H: $\mathrm{CpG}$ island hypermethylation as a biomarker for the early detection of lung cancer. In: Cancer Epigenetics. Humana Press, NY, USA, pp141-171, 2015.

8. Leygo C, Williams M, Jin HC, Chan MWY, Chu WK, Grusch M and Cheng YY: DNA methylation as a noninvasive epigenetic biomarker for the detection of cancer. Dis Markers 2017: $3726595,2017$.

9. Herman JG, Graff JR, Myöhänen S, Nelkin BD and Baylin SB: Methylation-specific PCR: A novel PCR assay for methylation status of CpG islands. Proc Natl Acad Sci USA 93: 9821-9826, 1996.

10. Navarro E, Serrano-Heras G, Castaño MJ and Solera J: Real-time PCR detection chemistry. Clin Chim Acta 439: 231-250, 2015.

11. Hulbert A, Jusue-Torres I, Stark A, Chen C, Rodgers K, Lee B, Griffin C, Yang A, Huang P, Wrangle J, et al: Early Detection of Lung Cancer Using DNA Promoter Hypermethylation in Plasma and Sputum. Clin Cancer Res 23: 1998-2005, 2017.

12. Brait M, Ling S, Nagpal JK, Chang X, Park HL, Lee J, Okamura J, Yamashita K, Sidransky D and Kim MS: Cysteine dioxygenase 1 is a tumor suppressor gene silenced by promoter methylation in multiple human cancers. PLoS One 7: e44951, 2012.

13. Minatani N, Waraya M, Yamashita K, Kikuchi M, Ushiku H, Kojo K, Ema A, Nishimiya H, Kosaka Y, Katoh H, et al: Prognostic significance of promoter DNA hypermethylation of cysteine dioxygenase 1 (CDO1) gene in primary breast cancer. PLoS One 11: e0144862, 2016.

14. Choi JI, Cho E-H, Kim SB, Kim R, Kwon J, Park M, Shin HJ, Ryu HS, Park SH and Lee KH: Promoter methylation of cysteine dioxygenase type 1: Gene silencing and tumorigenesis in hepatocellular carcinoma. Ann Hepatobiliary Pancreat Surg 21: 181-187, 2017.

15. Igarashi K, Yamashita K, Katoh H, Kojima K, Ooizumi Y, Nishizawa N, Nishiyama R, Kawamata H, Tajima H,Kaizu T, et al: Prognostic significance of promoter DNA hypermethylation of the cysteine dioxygenase 1 (CDO1) gene in primary gallbladder cancer and gallbladder disease. PLoS One 12: e0188178, 2017.

16. Vedeld HM, Andresen K, Eilertsen IA, Nesbakken A, Seruca R, Gladhaug IP, Thiis-Evensen E, Rognum TO, Boberg KM and Lind GE: The novel colorectal cancer biomarkers CDO1, ZSCAN18 and ZNF331 are frequently methylated across gastrointestinal cancers. Int J Cancer 136: 844-853, 2015.

17. Meller S, Zipfel L, Gevensleben H, Dietrich J, Ellinger J, Majores M, Stein J, Sailer V, Jung M, Kristiansen G, et al: CDO1 promoter methylation is associated with gene silencing and is a prognostic biomarker for biochemical recurrence-free survival in prostate cancer patients. Epigenetics 11: 871-880, 2016.

18. Kwon J, Park M, Kim JH, Lee HW, Kang MC and Park JH: Epigenetic regulation of the novel tumor suppressor cysteine dioxygenase 1 in esophageal squamous cell carcinoma. Tumour Biol 36: 7449-7456, 2015.

19. Feng N, Wang Y, Zheng M, Yu X, Lin H, Ma RN, Shi O, Zheng X, Gao M, Yu H, et al: Genome-wide analysis of DNA methylation and their associations with long noncoding RNA/mRNA expression in non-small-cell lung cancer. Epigenomics 9: 137-153, 2017.

20. Goldstraw P, Chansky K, Crowley J, Rami-Porta R, Asamura H, Eberhardt WE, Nicholson AG, Groome P, Mitchell A, Bolejack V, et al; International Association for the Study of Lung Cancer Staging and Prognostic Factors Committee, Advisory Boards, and Participating Institutions; International Association for the Study of Lung Cancer Staging and Prognostic Factors Committee Advisory Boards and Participating Institutions: The IASLC Lung Cancer Staging Project: Proposals for Revision of the TNM Stage Groupings in the Forthcoming (Eighth) Edition of the TNM Classification for Lung Cancer. J Thorac Oncol 11: 39-51, 2016.

21. Kwon YJ, Lee SJ, Koh JS, Kim SH, Lee HW, Kang MC, Bae JB, Kim YJ and Park JH: Genome-wide analysis of DNA methylation and the gene expression change in lung cancer. J Thorac Oncol 7: 20-33, 2012.

22. Wrangle J, Machida EO, Danilova L, Hulbert A, Franco N, Zhang W, Glöckner SC, Tessema M, Van Neste L, Easwaran $\mathrm{H}$, et al: Functional identification of cancer-specific methylation of CDO1, HOXA9, and TAC1 for the diagnosis of lung cancer. Clin Cancer Res 20: 1856-1864, 2014. 
23. Ooki A, Maleki Z, Tsay JJ, Goparaju C, Brait M, Turaga N, Nam HS, Rom WN, Pass HI, Sidransky D, et al: A Panel of Novel Detection and Prognostic Methylated DNA Markers in Primary Non-Small Cell Lung Cancer and Serum DNA. Clin Cancer Res 23: 7141-7152, 2017.

24. Diaz-Lagares A, Mendez-Gonzalez J, Hervas D, Saigi M, Pajares MJ, Garcia D, Crujerias AB, Pio R, Montuenga LM, Zulueta J, et al: A Novel Epigenetic Signature for Early Diagnosis in Lung Cancer. Clin Cancer Res 22: 3361-3371, 2016.

25. Brait M, Ling S, Nagpal JK, Chang X, Park HL, Lee J, Okamura J, Yamashita K, Sidransky D and Kim MS: Cysteine dioxygenase 1 is a tumor suppressor gene silenced by promoter methylation in multiple human cancers. PLoS One 7: e44951, 2012.

26. Ramalho-Carvalho J, Henrique $\mathrm{R}$ and Jerónimo $\mathrm{C}$ : Methylation-specific PCR. In: DNA Methylation Protocols. Vol. 1708. Tost J (ed). Springer, Humana Press, New York, NY, pp447-472, 2018.

27. Holmes EE, Jung M, Meller S, Leisse A, Sailer V, Zech J, Mengdehl M, Garbe LA, Uhl B, Kristiansen G, et al: Performance evaluation of kits for bisulfite-conversion of DNA from tissues, cell lines, FFPE tissues, aspirates, lavages, effusions, plasma, serum, and urine. PLoS One 9: e93933, 2014.
28. López-Otín C, Blasco MA, Partridge L, Serrano M and Kroemer G: The hallmarks of aging. Cell 153: 1194-1217, 2013.

29. Derhovanessian E, Solana R, Larbi A and Pawelec G: Immunity, ageing and cancer. Immun Ageing 5: 11, 2008.

30. Rodier F and Campisi J: Four faces of cellular senescence. J Cell Biol 192: 547-556, 2011.

31. Bakulski KM and Fallin MDJE: Epigenetic epidemiology: Promises for public health research. Environ Mol Mutagen 55: 171-183, 2014.

32. Levine ME, Hosgood HD, Chen B, Absher D, Assimes T and Horvath S: DNA methylation age of blood predicts future onset of lung cancer in the women's health initiative. Aging (Albany NY) 7: 690-700, 2015.

33. Breitling LP, Yang R, Korn B, Burwinkel B and Brenner H: Tobacco-smoking-related differential DNA methylation: 27K discovery and replication. Am J Hum Genet 88: 450-457, 2011. 